\title{
DIVERSIDAD DE BACTERIAS ENDÓFITAS CULTIVABLES ASOCIADAS A PLANTAS DE ARÁNDANO (Vaccinium corymbosum L.) cv. Biloxi CON ACTIVIDADES PROMOTORAS DEL CRECIMIENTO VEGETAL
}

\section{DIVERSITY OF CULTIVABLE ENDOPHYTIC BACTERIA ASSOCIATED WITH BLUEBERRY PLANTS (Vaccinium corymbosum L.) cv. Biloxi WITH PLANT GROWTH-PROMOTING TRAITS}

\section{Magdalena A. Ortiz-Galeana ${ }^{1}$, Julie E. Hernández-Salmerón ${ }^{1}$, Brenda Valenzuela-Aragón ${ }^{2}$, Sergio} de los Santos-Villalobos ${ }^{3}$, Ma. del Carmen Rocha-Granados ${ }^{4}$ y Gustavo Santoyo ${ }^{1 *}$

${ }^{1}$ Laboratorio de Diversidad Genómica, Instituto de Investigaciones Químico Biológicas, Universidad Michoacana de San Nicolás de Hidalgo, Morelia, Michoacán, México.

${ }^{2}$ Laboratorio de Biotecnología del Recurso Microbiano, Instituto Tecnológico de Sonora Ciudad Obregón, Sonora, México.

${ }^{3}$ CONACYT-Instituto Tecnológico de Sonora, Ciudad Obregón, Sonora, México.

${ }^{4}$ Facultad de Agrobiología "Presidente Juárez", Universidad Michoacana de San Nicolás de Hidalgo, Uruapan, Michoacán, México.

*Autor para correspondencia E-mail: gsantoyo@umich.mx

\section{RESUMEN}

En el presente trabajo se explora la diversidad de bacterias endófitas cultivables asociadas a plantas de arándano (Vaccinium corymbosum L.) cv. Biloxi, así como la caracterización de sus actividades promotoras del crecimiento vegetal, incluyendo la producción de ácido indolacético (AIA), biofilm, sideróforos y actividad proteolítica. Los endófitos bacterianos fueron aislados de los diferentes tejidos de plantas de arándano, obteniendo una mayor densidad poblacional de bacterias endófitas en raíz, comparado con tallo y hojas. Al amplificar y secuenciar el gen ribosomal $16 \mathrm{~S}$ de los 92 aislados endófitos, las búsquedas tipo Blast en el National Center for Biotechnology Information (NCBI), así como los análisis filogenéticos, mostraron la identificación de 24 especies bacterianas, distribuidas en 4 Filos, tales como Bacteroidetes (1,1\%), Actinobacterias (23,9\%), Firmicutes (12,5\%) y Proteobacterias $(62,5 \%)$. Los géneros más abundantes fueron Pantoea, Pseudomonas, Burkholderia y Bacillus, entre otros. Al analizar algunas actividades promotoras del crecimiento vegetal, el $42 \%$ de los aislados endófitos mostraron al menos una actividad promotora del crecimiento vegetal. Interesantemente, algunas cepas de Bacillus y Pantoea mostraron mejor producción de fitohormonas (AIA), biofilm y sideróforos comparado con la rizobacteria Pseudomonas fluorescens UM270, utilizada como control positivo. Estos resultados muestran el posible papel benéfico que tienen los endófitos bacterianos en plantas de arándano, así como su potencial para ser empleados como bioinoculantes en otros cultivos de importancia agrícola.

Palabras clave: endófitos bacterianos, bacterias promotoras del crecimiento vegetal, diversidad genética, Vaccinium, arándano. 


\section{ABSTRACT}

The present work explores the diversity of cultivable endophytic bacteria associated with blueberry plants (Vaccinium corymbosum L.) cv. Biloxi, and characterizes their plant growth promoting activities, including the production of indoleacetic acid (AIA), biofilm, siderophores and proteolytic activity. Bacterial endophytes were isolated from different tissues of blueberry plants. A higher population density of endophytic bacteria was obtained from roots compared stems and leaves. BLAST and phylogenetic analysis, based on $16 \mathrm{~S}$ ribosomal gene sequencing, showed the identification of 24 bacterial species distributed in 4 Phyla, such as Bacteroidetes (1.1\%), Actinobacteria (23.9\%), Firmicutes (12.5\%) and Proteobacteria (62.5\%). The most abundant genera were Pantoea, Pseudomonas, Burkholderia and Bacillus, among others. When analyzing some plant growth-promoting activities, $42 \%$ of the endophyte isolates showed at least one beneficial activity. Interestingly, some strains of Bacillus and Pantoea showed better production of phytohormones (AIA), biofilm and siderophores compared to the well-known PGPR Pseudomonas fluorescens UM270. These results show that the bacterial endophytes could play a beneficial role in blueberry plants, and be potentially used as bioinoculants in other crops of agricultural importance.

Key words: bacterial endophytes, plant growth-promoting bacteria, genetic diversity, Vaccinium, blueberry.

\section{INTRODUCCIÓN}

El microbioma vegetal incluye las diversas comunidades que se encuentran asociadas con las plantas, incluyendo aquellas que residen dentro de sus tejidos (Santoyo et al., 2016). Las bacterias endófitas pueden habitar dentro de los tejidos vegetales sin provocar ningún daño, ya sean raíces, tallos, hojas, flores o semillas (Hallman et al., 1997). Diversos trabajos han demostrado que las bacterias endófitas son capaces de interactuar de una manera muy eficiente con sus hospederos, comparado con aquellas que habitan la filósfera o rizósfera (Ali et al., 2014). De hecho, se ha propuesto a la rizósfera -uno de los ecosistemas más diversos- como una fuente de adquisición de endófitos para las plantas, ya que las grietas de las raíces, así como las diversas heridas de tejidos que ocurren como resultado del crecimiento de la planta, entre otros daños mecánicos, permiten a las bacterias rizosféricas penetrar y colonizar los tejidos internos (Sørensen y Sessitsch, 2007). En un trabajo de Márquez-Santacruz et al. (2010) reportaron que existe una mayor diversidad de filotipos en la rizósfera de plantas de tomate verde (Physalis ixocarpa) comparado con la diversidad de endófitos bacterianos. Sin embargo, la gran mayoría de los filotipos de endófitos bacterianos fueron detectados en el ambiente rizosférico, corroborando que dicho microecosistema es una fuente potencial de bacterias endófitas.

Numerosos estudios han documentado los efectos benéficos de las bacterias endófitas, tales como promoción del crecimiento y protección vegetal contra la infección de fitopatógenos (Becerra-Castro et al., 2011; Zgadzaj et al., 2015; Contreras et al., 2016) Además, se ha demostrado que los endófitos bacterianos son capaces de inducir vías de resistencia en plantas, aumentando las capacidades de sobrevivir a diversos tipos de estrés ambiental, como el abiótico, salino, entre otros (Sziderics et al., 2007, Doty et al., 2009, Ali et al., 2014) . Los mecanismos benéficos que llevan a cabo las especies endófitas durante la interacción con plantas se han catalogado como directos e indirectos (Glick, 2014). Los mecanismos directos de promoción del crecimiento vegetal incluyen la producción de proteasas, sideróforos, fitohormonas como el ácido indolacético (AIA), y compuestos como el cianuro de hidrógeno (HCN), entre otros (Glick, 2014; Santoyo et al., 2018). Por otra parte, los mecanismos indirectos incluyen las acciones inhibitorias, antagónicas o de control biológico de potenciales fitopatógenos. Sin embargo, la producción de algunos compuestos podría traslaparse entre mecanismos directos e indirectos, pudiendo jugar un papel importante durante el biocontrol de patógenos y al mismo tiempo, mejorar la nutrición de la planta. Por ejemplo, la producción de sideróforos, la actividad ACC desaminasa o la producción de HCN (Glick, 2014). De forma interesante, el HCN tiene funciones como elicitor de la respuesta sistémica inducida, así como promotor del crecimiento y de antagonista contra hongos fitopatógenos (Huang et al., 2012; Meldau et al., 2013).

Un paso importante para conocer las actividades benéficas de las bacterias endófitas de las plantas es conocer su diversidad, y hasta ahora, cada planta que se ha analizado en diversas partes del mundo ha demostrado que contienen microorganismos endófitos, siendo las clases $\alpha, \beta$ y $\gamma$-Proteobacteria de las más comúnmente reportadas, seguido de las clases Actinobacteria, Firmicutes, Bacteroidetes, Planctomycetes y 
Verrucomicrobia. Cabe destacar que la diversidad y densidad de endófitos depende de diversos factores abióticos (i.e. la localización geográfica) y bióticos (i.e. la especie vegetal hospedera), y que son pocos los trabajos que han reportado dichos análisis (Pérez-Cordero et al., 2010). En cuanto a los géneros detectados como endófitos, Bacillus, Pseudomonas, Burkholderia, Stenotrophomonas, Micrococcus, Pantoea y Microbacterium están entre los más abundantes y comúnmente reportados (Hallmann et al., 1997; Márquez-Santacruz et al., 2010; Friesen et al., 2011). Así mismo, dentro de los géneros antes mencionados, son varios los que exhiben mecanismos directos e indirectos de promoción del crecimiento vegetal (Rosenblueth y Martínez-Romero, 2006).

El Estado de Michoacán, en México, es uno de los principales productores de frutillas o "berries" en el país, incluyendo zarzamora, fresa, frambuesa y arándano. De la producción total de frutillas en México, el $80 \%$ se exporta a otras regiones del mundo (www.sagarpa.gob.mx). Dado que existen diversas regulaciones internacionales para importar/exportar productos sin agroquímicos, es necesario implementar estrategias, como el desarrollo de bioinoculantes que promuevan el crecimiento vegetal y combatan las plagas en los cultivos, y que no contaminen el ambiente, ni sean un riesgo para la salud humana.

Consistente con lo anterior, en este trabajo se aisló y se caracterizó por medio de la secuenciación de los genes 16S rDNA la diversidad de comunidades bacterianas endófitas de plantas de arándano de cultivos ubicados en el Estado de Michoacán, México. Así mismo, se determinó el grupo de especies endófitas con la capacidad potencial para promover el desarrollo vegetal.

\section{MATERIALES Y MÉTODOS}

\section{Muestras vegetales}

Se aislaron las bacterias endófitas de un total de 12 plantas de arándano (Vaccinium corymbosum L.) cv. Biloxi. Las plantas de dos meses de edad, en fase de crecimiento vegetativo y sin síntomas de daños por fitopatógenos, fueron colectadas de invernaderos localizados en Uruapan $\left(19^{\circ} 25^{\prime} 16^{\prime \prime}\right.$ N, 10203'47" O), Michoacán, México.

\section{Aislamiento de bacterias endófitas}

Los tejidos de raíz, tallo y hojas se separaron para ser analizados de forma independiente, los cuales se lavaron con agua destilada estéril. En caso de las raíces se retiraron cuidadosamente las partículas adheridas de suelo. Posteriormente, se obtuvieron $1 \mathrm{~g}$ de tejido de cada órgano de cada planta y se esterilizaron superficialmente como se ha reportado previamente para aislar los endófitos bacterianos (Contreras et al., 2016). En breve, las raíces se sumergieron en etanol al 70\% durante 30 segundos, se lavaron con solución de hipoclorito de sodio fresco $\left(2,5 \%\right.$ de $\left.\mathrm{Cl}^{-}\right)$durante $5 \mathrm{~min}$, se lavaron con etanol al $70 \%$ durante 30 seg y finalmente se lavaron de cinco a diez veces con agua destilada estéril. Para confirmar aún más que el proceso de esterilización fue bueno, alícuotas del agua destilada estéril usada en el enjuague final se esparcieron en cajas Petri con medio agar nutritivo. Las placas se examinaron para el crecimiento bacteriano después de la incubación a $28^{\circ} \mathrm{C}$ durante 4 días, sin observar crecimiento bacteriano. Se realizaron tres réplicas independientes de diluciones seriadas por gramo de tejido fresco de hoja, tallo y raíz, previamente macerado en morteros estériles, para obtener la densidad bacteriana cultivable. Para lo cual, se tomaron $100 \mu \mathrm{L}$ de cada dilución para ser dispersados en cajas de Petri conteniendo agar nutritivo al $20 \%$, las cuales se incubaron por 72 horas a $30^{\circ} \mathrm{C}$, realizando conteos de las unidades formadoras de colonias (UFC) al final de dicho periodo por gramos de peso fresco de cada tejido analizado.

\section{Caracterización molecular de aislados endófitos}

Se aisló el ADN genómico de 92 cepas bacterianas seleccionadas al azar. Se utilizaron los oligonucleótidos bacterianos fD1 y rD1 (Weisburg et al., 1991) para amplificar y secuenciar el gen ribosomal 16S. Las condiciones de PCR se han informado previamente (Márquez-Santacruz et al., 2010). Todos los productos de PCR se purificaron y secuenciaron en Mr. DNA (Texas, U.S.). Las secuencias de $16 \mathrm{~S}$ rADN obtenidas se sometieron a búsquedas de tipo Blast contra las bases de datos del GenBank (NCBI).

\section{Análisis filogenético}

Se generaron múltiples alineamientos de secuencias de ADN y se realizó el análisis filogenético de las secuencias del gen 16S rDNA con el programa MEGA 5.0 (Tamura et al., 2011). Todas las secuencias pasaron controles de calidad y con el fin de obtener un valor de confianza para el conjunto de datos de secuencias alineadas, se realizó un análisis de bootstrap de 1000 repeticiones. Un árbol filogenético se construyó mediante el algoritmo de máxima verosimilitud. Otros métodos mostraron topologías similares.

\section{Identificación de actividades promotoras del crecimiento vegetal}

Se usaron placas de agar de Skim Milk (SM) para detectar la producción y actividad de proteasas (Kumar et al., 2005). La producción de sideróforos se determinó mediante el ensayo de 
cromo azurol S (CAS) (Schwyn y Neilands, 1987). Los experimentos se realizaron por triplicado y en ambos casos para la actividad proteolítica y producción de sideróforos se determinó midiendo el halo formado por cada aislado en el determinado medio de cultivo. La producción de ácido indol-3-acético (IAA) se analizó como se publicó previamente en Hernández-León et al. (2015). Se usó GC-MS (Gas Chromatograph 6850 Series II - Detector de Espectrometría de Masas 5973, Agilent, Foster City, California, USA) para su análisis. La identidad del AIA se confirmó mediante la comparación del tiempo de retención en los extractos bacterianos con muestras del estándar de IAA (Sigma-Aldrich). Las cantidades de AIA producidas por los aislados bacterianos se estimaron utilizando curvas de calibración. La capacidad de formación de biofilm en las bacterias se analizó siguiendo el protocolo de Wei y Zhang (1996), donde se emplea cristal violeta al 0,1\% para teñir las células adheridas a tubos Eppendorf y se mide la D.O. en un espectrofotómetro una longitud de onda a $570 \mathrm{~nm}$.. Los experimentos se realizaron por triplicado.

\section{RESULTADOS Y DISCUSIÓN}

\section{Población y diversidad bacteriana, y su relación filogenética}

Los endófitos bacterianos fueron aislados de los diferentes tejidos de plantas de arándano, obteniendo las siguientes unidades formadoras de colonia por gramos de peso freso ( $\mathrm{UFC} \mathrm{g}^{-1}$ ); en raíces fue de $1,0 \times 10^{5} \pm 0,8 \times 10^{5}$, mientras que en hojas encontramos una densidad de 5,5 $\times 10^{4}$ $\pm 0,5 \times 10^{4}$, y para tallo fue de $2,0 \times 10^{4} \pm 0,2 \times 10^{4}$, siendo este último el tejido con menor población de bacterias endófitas (Fig. 1).

Para tener una representación de la diversidad bacteriana cultivable en plantas de $V$. corymbosum L. cv. Biloxi se seleccionaron aleatoriamente aislados axénicos para la secuenciación del gen ribosomal 16S. Así, mediante búsquedas de homología tipo Blast, se detectaron 24 especies bacterianas diferentes $\mathrm{u}$ OTUs (Unidades Taxonómicas Operacionales). Los OTUs encontrados pertenecen a 4 Filos, incluyendo Bacteroidetes (1,1\%), Actinobacterias (23,9), Firmicutes $(12,5 \%)$ y Proteobacterias, las cuales fueron las más abundantes $(62,5 \%)$. Con respecto a las especies, encontramos que 16 aislados pertenecen a Pantoea agglomerans (17,4\%), Pseudomonas protegens $(10,8 \%)$, Streptomyces griseocarneus $(9,7 \%)$ y Burkholderia contaminans $(8,7 \%)$. Otras especies menos abundantes fueron Azoarcus evansii, Bacillus cereus, Microbacterium terrae, Sphingopyxis taejonensis, entre otros (Fig. 2).

Elgen ribosomal 16S analizadoen los 92 aislados endófitos asociados de los diferentes tejidos de $V$. corymbosum L. cv. Biloxi muestran estrechas relaciones con la mayoría de especies bacterianas identificadas en el GenBank, con identidades y coberturas mayores al $97 \%$, representando los 4 Filos encontrados: Bacteroidetes, Actinobacterias, Firmicutes y Proteobacterias (Fig. 3). Dentro de nuestro análisis y búsqueda de homologías, los aislados denominados PEV59, PEV70, PEV72 y PEV75, no presentaron identidad con genes

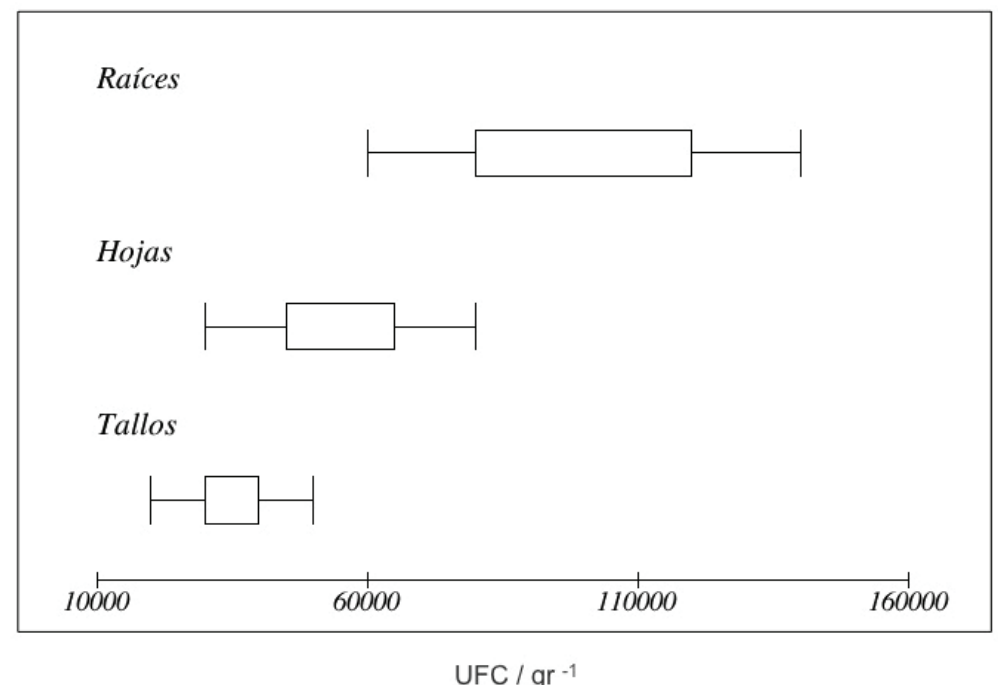

Fig. 1. Densidad poblacional de bacterias endófitas cultivables en tres tejidos de plantas de arándano: raíz, tallo y hoja. Ver texto para detalles.

Fig. 1. Population density of cultivable endophytic bacteria in three different tissues of blueberry plants: root, stem and leaf. See text for details. 


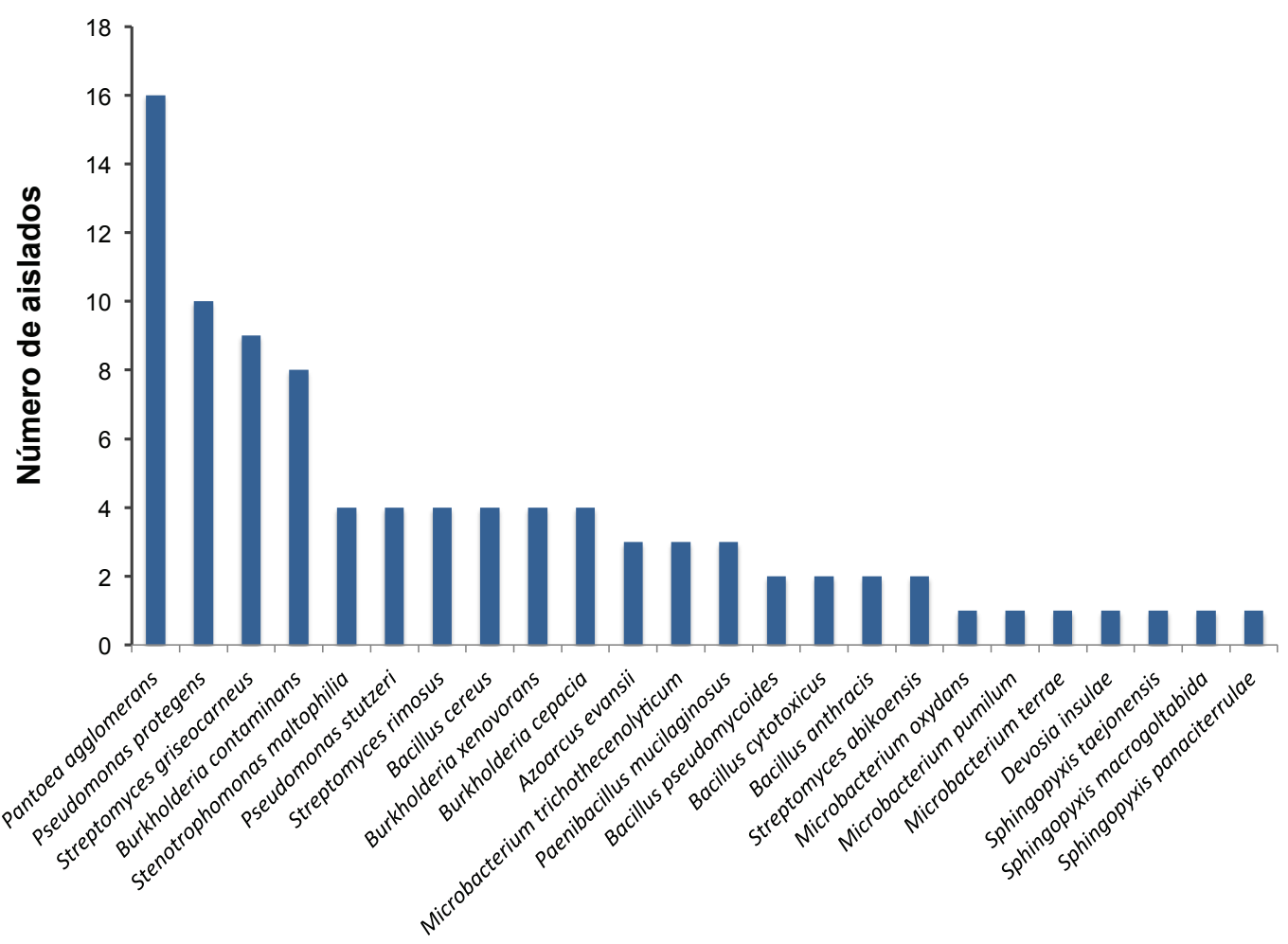

Fig. 2. Especies y número total de aislados endófitos cultivables encontrados en plantas de arándano. Ver texto para detalles.

Fig. 2. Species and total number of cultivable endophytic isolates found in blueberry plants. See text for details.

ribosomales mayor al 97\%. Lo anterior necesita una caracterización molecular más exhaustiva para asignar a que especie pertenecen (Tabla suplementaria).

Se ha propuesto que los microbiomas o microorganismos asociados a las plantas constituyen un segundo genoma vegetal (Turner et al., 2013). Las interacciones entre el microbioma y las plantas pueden ser diversas; sin embargo, aquellas benéficas como la promoción del crecimiento vegetal y biocontrol de fitopatógenos son importantes para su uso agro-biotecnológico (entre otras muchas aplicaciones). En este trabajo, se destaca que el grupo dominante es el filo Proteobacterias, y Clase Gammaproteobacteria, lo cual es consistente con otros estudios (MárquezSantacruz et al., 2010). Los géneros bacterianos Pantoea, Pseudomonas, Streptomyces, Burkholderia y Bacillus fueron encontrados en este análisis como endófitos de las plantas de arándano. En el caso de Pantoea, ha sido reportado como endófito residente de diferentes plantas, como el arroz y vid (uva) (Elvira-Recuenco y van Vuurde, 2000; Andreolli et al., 2016). Una cepa (TR-5) de Pantoea ananatis aislada de granos de maíz inhibió in vitro el crecimiento del hongo Lecanicillium aphanocladii (Zinniel et al., 2002).

Los géneros Pseudomonas y Burkholderia han sido ampliamente estudiados por la producción y emisión de su diversa gama de productos metabólicos secundarios incluyendo antibióticos, como las fenazinas, el 2,4-diacetilfloroglucinol, compuestos orgánicos volátiles antifúngicos como el ácido cianhídrico, la dimetilhexadecilamina o el dimetildisulfuro (Hernández-León et al., 2015). Las especies como Bacillus thuringiensis producen proteínas Cry con actividad insecticidas, mientras que otros compuestos como los sideróforos también pueden inhibir el crecimiento de micelio a través de la captación de hierro, haciéndolo menos disponible para los patógenos (MartínezAbsalón et al., 2014). Las especies pertenecientes al género de Stenotrophomonas han sido aisladas o detectadas como endófitas de raíces de arroz (Sun et al., 2008), raíces y tallos de algodón (McInroy y Kloepper, 1995). Algunos estudios proponen a Stenotrophomonas como bacterias promotoras del crecimiento de las plantas, y que podrían suprimir el desarrollo de la enfermedad por secreción de algunos compuestos, como el 


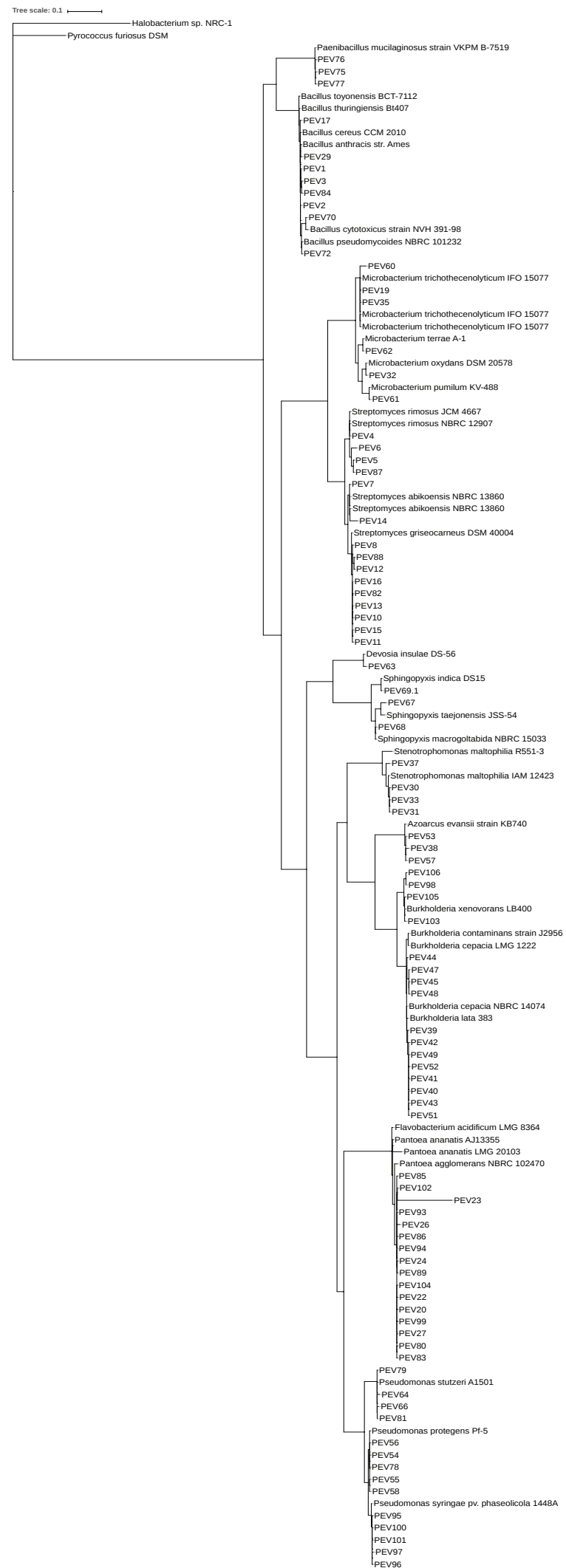

Fig. 3. Relaciones filogenéticas de 92 bacterias endófitas cultivables de plantas de arándano. Ver texto para detalles.

Fig. 3. Phylogenetic relationships of 92 cultivable endophytic bacteria of blueberry plants. See text for details. 
antibiótico maltofilina (Jakovi et al., 1996).

Otro grupo de bacterias en plantas de arándano loconstituyen endófitas del género Microbacterium, el cual se ha reportado en asociación endofítica con diferentes plantas (Conn y Franco, 2004; Santoyo et al., 2016). De hecho, Conn y Franco (2004) reportaron varias especies de Microbacterium en un análisis de las poblaciones endofíticas en las raíces de trigo (Triticum aestivum L.), siendo el género predominante dentro de la comunidad bacteriana endófitica. Lo anterior, junto con otros reportes, muestran que las bacterias endófitas se encuentran asociadas a gran parte de las plantas de interés comercial que se han estudiado i.e. arroz (Oryza sativa), banano (Musa acuminata), trigo (Triticum aestivum), zarzamora (Rubus fruticosus), caña de azúcar (Saccharum spp.), zanahoria (Daucus carota), maíz (Zea mays), papa (Ipomoea batatas), uva (Vitis vinifera), entre otros (Rosenblueth y Martínez-Romero, 2006; Andreolli et al., 2016; Contreras et al., 2016).

Tabla suplementaria.

\begin{tabular}{|c|c|c|c|c|}
\hline Cepa & $\begin{array}{l}\text { Especie/Cepa con mayor identidad en el } \\
\text { NCBI }\end{array}$ & $\begin{array}{l}\text { Pares de } \\
\text { bases }\end{array}$ & $\begin{array}{c}\% \\
\text { identidad }\end{array}$ & $\begin{array}{c}\mathbf{N}^{o .} \\
\text { de acceso }\end{array}$ \\
\hline PEV1 & Bacillus thuringiensis Bt407 & 1236 & $99 \%$ & NR_102506.1 \\
\hline PEV2 & Bacillus anthracis str. Ames & 1502 & $99 \%$ & NR_074453.1 \\
\hline PEV3 & Bacillus toyonensis BCT-7112 & 1544 & $99 \%$ & NR_121761.1 \\
\hline PEV4 & Streptomyces rimosus NBRC 12907 & 1120 & $100 \%$ & NR_112332.1 \\
\hline PEV5 & Streptomyces rimosus JCM 4667 & 980 & $99 \%$ & NR_024762.1 \\
\hline PEV6 & Streptomyces rimosus NBRC 12907 & 683 & $99 \%$ & NR_112332.1 \\
\hline PEV7 & Streptomyces abikoensis NBRC 13860 & 1180 & $100 \%$ & NR_118286.1 \\
\hline PEV8 & Streptomyces griseocarneus DSM 40004 & 1357 & $99 \%$ & NR_026355.1 \\
\hline PEV10 & Streptomyces griseocarneus DSM 40004 & 1147 & $99 \%$ & NR_026355.1 \\
\hline PEV11 & Streptomyces griseocarneus DSM 40004 & 1027 & $99 \%$ & NR_026355.1 \\
\hline PEV12 & Streptomyces griseocarneus DSM 40004 & 1026 & $99 \%$ & NR_026355.1 \\
\hline PEV13 & Streptomyces griseocarneus DSM 40004 & 929 & $99 \%$ & NR_026355.1 \\
\hline PEV14 & Streptomyces abikoensis NBRC 13860 & 766 & $99 \%$ & NR_118287.1 \\
\hline PEV15 & Streptomyces griseocarneus DSM 40004 & 1133 & $99 \%$ & NR_026355.1 \\
\hline PEV16 & Streptomyces griseocarneus DSM 40004 & 1117 & $99 \%$ & NR_026355.1 \\
\hline PEV17 & Bacillus cereus CCM 2010 & 1506 & $99 \%$ & NR_115714.1 \\
\hline PEV19 & Microbacterium trichothecenolyticum IFO 15077 & 732 & $99 \%$ & NR_112002.1 \\
\hline PEV20 & Pantoea ananatis AJ13355 & 1542 & $99 \%$ & NR_074740.1 \\
\hline PEV22 & Pantoea ananatis AJ13355 & 1417 & $99 \%$ & NR_074740.1 \\
\hline PEV23 & Pantoea agglomerans NBRC 102470 & 1337 & $99 \%$ & NR_114111.1 \\
\hline PEV24 & Pantoea ananatis LMG 20103 & 1334 & $99 \%$ & NR_103927.1 \\
\hline PEV26 & Pantoea ananatis LMG 20103 & 1140 & $99 \%$ & NR_103927.1 \\
\hline PEV27 & Pantoea ananatis LMG 20103 & 1227 & $99 \%$ & NR_103927.1 \\
\hline PEV29 & Bacillus anthracis str. Ames & 1399 & $99 \%$ & NR_074453.1 \\
\hline PEV30 & Stenotrophomonas maltophilia IAM 12423 & 1218 & $99 \%$ & NR_041577.1 \\
\hline PEV31 & Stenotrophomonas maltophilia R551-3 & 886 & $99 \%$ & NR_074875.1 \\
\hline PEV32 & Microbacterium oxydans DSM 20578 & 1325 & $99 \%$ & NR_044931.1 \\
\hline PEV33 & Stenotrophomonas maltophilia R551-3 & 775 & $99 \%$ & NR_074875.1 \\
\hline PEV35 & Microbacterium trichothecenolyticum IFO 15077 & 716 & $99 \%$ & NR_112002.1 \\
\hline PEV37 & Stenotrophomonas maltophilia IAM 12423 & 901 & $99 \%$ & NR_041577.1 \\
\hline PEV38 & Azoarcus evansii KB740 & 1498 & $99 \%$ & NR_029266.1 \\
\hline PEV39 & Burkholderia lata 383 & 1385 & $99 \%$ & NR_102890.1 \\
\hline PEV40 & Burkholderia lata 383 & 1314 & $99 \%$ & NR_102890.1 \\
\hline PEV41 & Burkholderia contaminans J2956 & 1137 & $99 \%$ & NR_104978.1 \\
\hline PEV42 & Burkholderia contaminans J2956 & 1127 & $99 \%$ & NR_104978.1 \\
\hline PEV43 & Burkholderia contaminans J2956 & 1103 & $99 \%$ & NR_104978.1 \\
\hline PEV44 & Burkholderia contaminans J2956 & 1330 & $99 \%$ & NR_104978.1 \\
\hline PEV45 & Burkholderia cepacia NBRC 14074 & 1223 & $99 \%$ & NR_113645.1 \\
\hline PEV47 & Burkholderia cepacia LMG 1222 & 871 & $99 \%$ & NR_118057.1 \\
\hline
\end{tabular}




\begin{tabular}{|c|c|c|c|c|}
\hline PEV49 & Burkholderia contaminans J2956 & 1120 & $99 \%$ & NR_104978.1 \\
\hline PEV51 & Burkholderia contaminans J2956 & 1012 & $99 \%$ & NR_104978.1 \\
\hline PEV52 & Burkholderia contaminans J2956 & 1126 & $99 \%$ & NR_104978.1 \\
\hline PEV55 & Azoarcus evansii KB740 & 1420 & $99 \%$ & NR_029266.1 \\
\hline PEV54 & Pseudomonas protegens Pf-5 & 1531 & $100 \%$ & NR_074599.1 \\
\hline PEV55 & Pseudomonas protegens Pf-5 & 1458 & $99 \%$ & NR_074599.1 \\
\hline PEV56 & Pseudomonas protegens Pf-5 & 1514 & $100 \%$ & NR_074599.1 \\
\hline PEV57 & Azoarcus evansii KB740 & 1310 & $99 \%$ & NR_029266.1 \\
\hline PEV58 & Pseudomonas protegens Pf-5 & 1447 & $100 \%$ & NR_074599.1 \\
\hline PEV59 & No se encontró similitud alguna & & & \\
\hline PEV60 & Microbacterium trichothecenolyticum IFO 15077 & 689 & $99 \%$ & NR_112002.1 \\
\hline PEV61 & Microbacterium pumilum KV-488 & 1049 & $99 \%$ & NR_041331.1 \\
\hline PEV62 & Microbacterium terrae $A-1$ & 1179 & $99 \%$ & NR_036760.1 \\
\hline PEV63 & Devosia insulae strain DS-56 & 1186 & $99 \%$ & NR_044036.1 \\
\hline PEV64 & Pseudomonas stutzeri A1501 & 1103 & $99 \%$ & NR_074829.1 \\
\hline PEV66 & Pseudomonas stutzeri A1501 & 968 & $99 \%$ & NR_074829.1 \\
\hline PEV67 & Sphingopyxis taejonensis JSS-54 & 904 & $98 \%$ & NR_024999.1 \\
\hline PEV68 & Sphingopyxis macrogoltabida NBRC 15033 & 1246 & $99 \%$ & NR_113720.1 \\
\hline PEV69 & Sphingopyxis indica DS15 & 1389 & $99 \%$ & NR_108185.1 \\
\hline PEV70 & No se encontró ninguna similitud & 928 & & \\
\hline PEV71 & Bacillus cytotoxicus NVH 391-98 & 1188 & $99 \%$ & NR_074914.1 \\
\hline PEV72 & No se encontró ninguna similitud & & & \\
\hline PEV74 & Bacillus pseudomycoides NBRC 101232 & 905 & $100 \%$ & NR_113991.1 \\
\hline PEV75 & No se encontró ninguna similitud & & & \\
\hline PEV76 & Paenibacillus mucilaginosus VKPM B-7519 & 1321 & $99 \%$ & NR_116536.1 \\
\hline PEV77 & Paenibacillus mucilaginosus VKPM B-7519 & 1115 & $99 \%$ & NR_116536.1 \\
\hline PEV78 & Paenibacillus mucilaginosus VKPM B-7519 & 1303 & $99 \%$ & NR_116536.1 \\
\hline PEV79 & Pseudomonas protegens Pf-5 & 1403 & $100 \%$ & NR_074599.1 \\
\hline PEV80 & Pseudomonas stutzeri A1501 & 1532 & $100 \%$ & NR_074829.1 \\
\hline PEV81 & Pantoea ananatis LMG 20103 & 1288 & $99 \%$ & NR_103927.1 \\
\hline PEV82 & Pseudomonas stutzeri A1501 & 1462 & $100 \%$ & NR_074829.1 \\
\hline PEV83 & Streptomyces griseocarneus DSM 40004 & 1093 & $99 \%$ & NR_026355.1 \\
\hline PEV84 & Pantoea ananatis AJ13355 & 1320 & $99 \%$ & NR_074740.1 \\
\hline PEV85 & Bacillus toyonensis BCT-7112 & 1103 & $99 \%$ & NR_121761.1 \\
\hline PEV86 & Pantoea ananatis AJ13355 & 1378 & $99 \%$ & NR_074740.1 \\
\hline PEV87 & Pantoea ananatis AJ13355 & 1322 & $99 \%$ & NR_074740.1 \\
\hline PEV88 & Streptomyces rimosus NBRC 12907 & 923 & $99 \%$ & NR_112332.1 \\
\hline PEV89 & Streptomyces griseocarneus DSM 40004 & 966 & $99 \%$ & NR_026355.1 \\
\hline PEV93 & Pantoea ananatis AJ13355 & 1320 & $99 \%$ & NR_074740.1 \\
\hline PEV94 & Pantoea ananatis AJ13355 & 1322 & $99 \%$ & NR_074740.1 \\
\hline PEV95 & Pantoea ananatis AJ13355 & 1271 & $99 \%$ & NR_074740.1 \\
\hline PEV96 & Pseudomonas syringae pv. phaseolicola $1448 \mathrm{~A}$ & 1470 & $99 \%$ & NR_074598.1 \\
\hline PEV97 & Pseudomonas syringae pv. phaseolicola $1448 \mathrm{~A}$ & 1413 & $99 \%$ & NR_074598.1 \\
\hline PEV98 & Pseudomonas syringae pv. phaseolicola $1448 \mathrm{~A}$ & 1408 & $99 \%$ & NR_074598.1 \\
\hline PEV99 & Burkholderia xenovorans LB400 & 1465 & $100 \%$ & NR_074325.2 \\
\hline PEV100 & Pantoea ananatis AJ13355 & 1432 & $99 \%$ & NR_074740.1 \\
\hline PEV101 & Pseudomonas syringae pv. phaseolicola 1448A; BAA-978 & 1533 & $99 \%$ & NR_074598.1 \\
\hline PEV102 & Pseudomonas syringae pv. phaseolicola $1448 A ; B A A-978$ & 1528 & $99 \%$ & NR_074598.1 \\
\hline PEV103 & Flavobacterium acidificum LMG 8364 & 1251 & $99 \%$ & NR_104962.1 \\
\hline PEV104 & Burkholderia xenovorans LB400 & 1330 & $100 \%$ & NR_074325.2 \\
\hline PEV105 & Burkholderia xenovorans LB400 & 2767 & $100 \%$ & NR_074325.2 \\
\hline PEV106 & Burkholderia xenovorans LB400 & 1398 & $100 \%$ & NR_074325.2 \\
\hline
\end{tabular}




\section{Caracterización de mecanismos de promoción del crecimiento vegetal}

Adicional a determinar la diversidad endófita bacteriana de $V$. corymbosum L. cv. Biloxi, y con el fin de explorar el potencial papel funcional de los aislados en los tejidos internos de la planta, se exploraron algunas actividades de promoción del crecimiento de plantas. En general, se encontró que aproximadamente el $42 \%$ de los aislados endófitos mostraron al menos una actividad benéfica (Fig. 4). Algunos aislados como Bacillus toyonensis PEV85 y Pantoea ananatis PEV86, mostraron una mayor producción de ácido indolacético, de 32 y $20 \mu \mathrm{g} \mathrm{mL}{ }^{-1}$, respectivamente, comparado con la rizobacteria promotora del crecimiento vegetal Pseudomonas fluorescens UM270 (HernándezLeón et al., 2015), que produce un promedio de $10 \mu \mathrm{g} \mathrm{mL}^{-1}$ (Fig. 4A). La Fig. 4, panel B, también muestra el análisis de algunos aislados endófitos como Pantoea agglomerans PEV20, PEV23, PEV27, Streptomyces griseocarneus PEV8, PEV11 y Bacillus cereus PEV17, los cuales tienen, en general, una significativa producción de biofilm a las 24, 48 y 72 horas, similar a la cepa UM270. Otros aislados no mostraron producción de biofilm o no fue significativa. Respecto a la producción de sideróforos, destacan cepas endófitas de Pseudomonas protegens, las cuales presentan un diámetro del halo de producción de sideróforos similar a UM270 en el medio CAS (Fig. 4C). En el panel D de la Fig. 4 también se muestra la actividad proteolítica de algunos aislados, los cuales mostraron un halo de degradación mayor comparado con la cepa UM270. Estos resultados muestran el posible papel benéfico que juegan los endófitos bacterianos en plantas de arándano.

Además de analizar la población y diversidad genética de bacterias endófitas cultivables de plantas de arándano, se buscaron actividades relacionadas con la promoción del crecimiento vegetal, incluyendo la producción de fitohormonas (ácido indolacético), producción de biofilm, sideróforos y preoteasas. Así, con el objetivo de identificar potenciales microorganismos promotores del crecimiento vegetal endófitos de cultivodearándano, se compararonlas capacidades de las bacterias endófitas con la cepa UM270 de Pseudomonas fluoresnces, la cual es una bacteria rizosférica con diversos mecanismos directos e indirectos de promoción del crecimiento vegetal ya reportados, además de presentar características de competencia y de colonización de la rizósfera de maíz (Hernández-León et al., 2015; Rojas-Solís et al., 2016). En este trabajo se encontró diferentes aislados con capacidades comparables o mayores que la cepa UM270. Por ejemplo, Bacillus toyonensis PEV85 y Pantoea ananatis PEV86 mostraron una mayor producción de ácido indolacético. Pantoea agglomerans PEV20, PEV23, PEV27, Streptomyces griseocarneus PEV8, PEV11 y Bacillus cereus PEV17 presentaron una buena producción de biofilm a diferentes tiempos, mientras que respecto a la producción de sideróforos, destacan cepas endófitas de Pseudomonas protegens. El aislado Burkholderia contaminans mostró una alta actividad proteolítica; sin embargo, es necesario analizar si dicha capacidad no tiene algún papel fitotóxico.

La producción de fitohormonas, como el AIA es una de las principales actividades que promueven el crecimiento y desarrollo de las plantas, ampliamente reportada en diversas especies bacterianas asociadas a plantas (Noh Medina et al., 2014; Hernández-León et al., 2015). Por otra parte, las bacterias interactúan físicamente con las superficies a través de la formación de biofilm o un conjunto complejo multicelular, que puede incluir a menudo múltiples especies. Danhorn y Fuqua (2007) proponen que existe una creciente apreciación de que la intensidad, la duración y el resultado de las interacciones entre las plantas y los microorganismos están significativamente influenciados por la conformación de las poblaciones microbianas adherentes. La capacidad de adhesión o "attachment" es necesaria para la formación de biofilm, lo cual permite que las bacterias interactúen con los tejidos vegetales, a través de adhesinas incluyendo polisacáridos y proteínas de superficie. Las bacterias rizosféricas con buena formación de biofilm, por lo tanto, son consideradas buenas colonizadoras de la rizósfera, capaces de adherirse la superficie de raíces y poder formar nódulos o penetrar los tejidos para convertirse en endófitas (Santoyo et al., 2016).

Los sideróforos microbianos son compuestos quelantes de hierro. Así, el hierro del suelo o de un ambiente endófito es captado por los sideróforos, los cuales actúan como sistemas de transporte del elemento hacia las bacterias y dentro de la planta, además de hacerlo menos disponible para los patógenos (Silver y Walderhaug, 1992). Se ha demostrado que mediante este mecanismo los sideróforos restringen el crecimiento de microorganismos que causan enfermedades en plantas (Weller, et al., 2002). Con respecto a la producción de enzimas líticas, se ha observado que cepas endófitas de maíz pertenecientes al género Bacillus, pueden inhibir hongos patógenos como Fusarium verticillioides, Colletotrichum graminicola, Bipolaris maydis y Cercospora zea-maydis (SzilagyiZecchin et al., 2014). Granér y colaboradores (2003) también observaron que bacterias endófitas aisladas de diferentes cultivares de Brassica napus con la capacidad de producir proteasas y celulasas, mostraron actividad antifúngica contra el patógeno de marchitez Verticillium longisporum. 


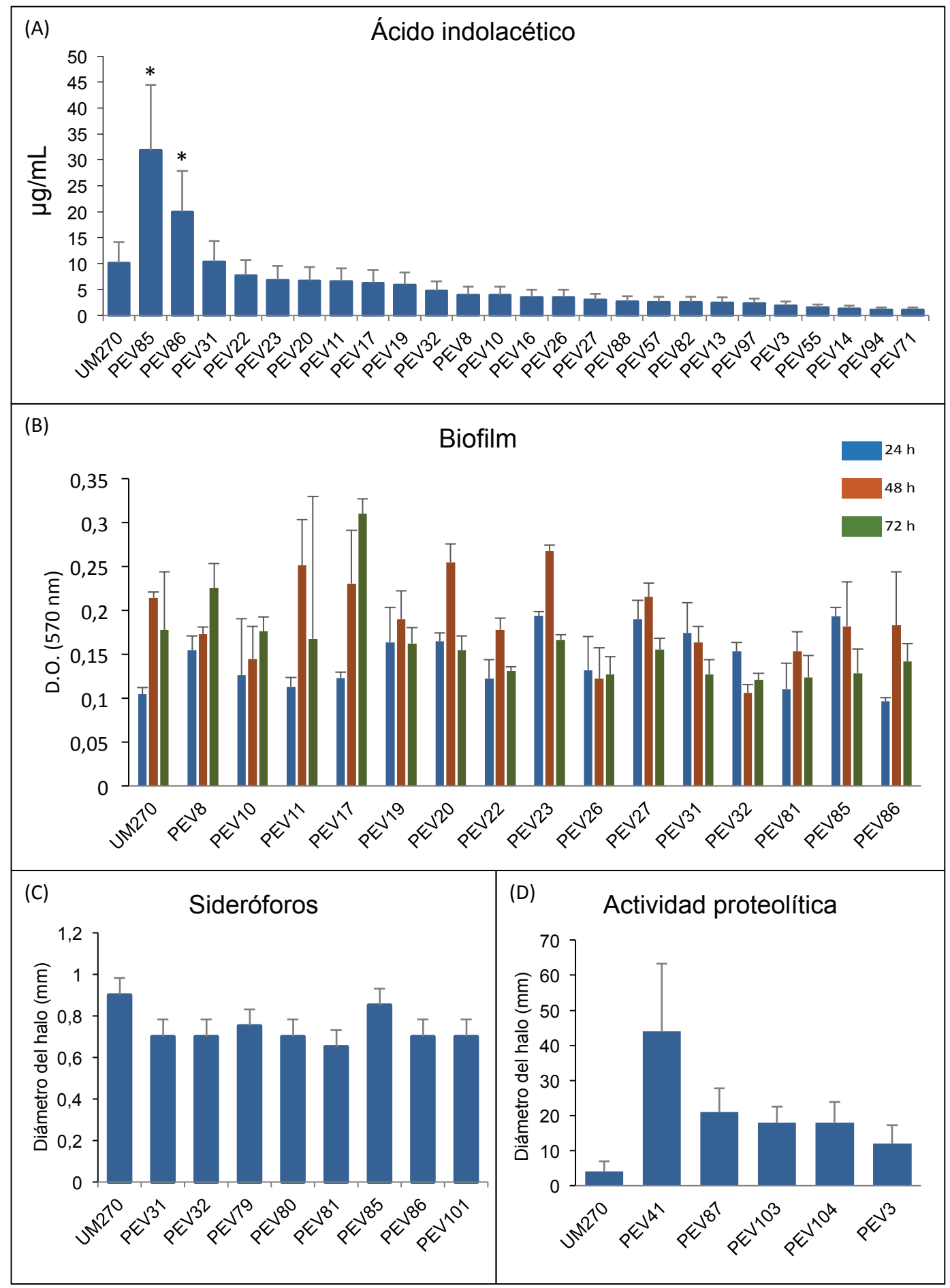

Fig. 4. Análisis de actividades promotoras del crecimiento vegetal en bacterias endófitas cultivables de plantas de arándano, incluyendo producción de ácido indolacético, biofilm, sideróforos y actividades proteolíticas. Ver texto para detalles.

Fig. 4. Analysis of plant growth-promoting activities in cultivable endophytic bacteria of blueberry plants, including production of indoleacetic acid, biofilm, siderophores and proteolytic activities. See text for details. 


\section{CONCLUSIÓN}

Las bacterias cultivables endófitas de arándano (Vaccinium corymbosum L.) cv. Biloxi muestran diversos mecanismos de promoción del crecimiento vegetal, ya sea directos e indirectos, siendo candidatos promisorios para su estudio y aplicación como inoculantes (biopromotores y biofungicidas) para el cultivo de arándano.

\section{AGRADECIMIENTOS}

Los autores agradecen al Consejo Nacional de Ciencia y Tecnología (México) (Proyecto No. 169346) y a la Coordinación de la Investigación Científica-Universidad Michoacana de San Nicolás de Hidalgo (2018-2019) por apoyar financieramente nuestros proyectos de investigación.

\section{LITERATURA CITADA}

Ali, S., Charles, T.C., and B.R. Glick. 2014. Amelioration of high salinity stress damage by plant growth-promoting bacterial endophytes that contain ACC deaminase. Plant Physiol. Biochem. 80:160-167.

Andreolli, M., S. Lampis, G. Zapparoli, E. Angelini, and G. Vallini. 2016. Diversity of bacterial endophytes in 3 and 15 year-old grapevines of Vitis vinifera cv. Corvina and their potential for plant growth promotion and phytopathogen control. Microbiol. Res. 183:42-52.

Becerra-Castro, C., P.S. Kidd, Á. Prieto-Fernández, N. Weyens., M.J. Acea, and J. Vangronsveld. 2011. Endophytic and rhizoplane bacteria associated with Cytisus striatus growing on hexachlorocyclohexane-contaminated soil: isolation and characterisation. Plant Soil 340:413-433.

Conn, V.M., and C. Franco. M. 2004. Analysis of the endophytic actinobacterial population in the roots of wheat (Triticum aestivum L.) by terminal restriction fragment length polymorphism and sequencing of 16S rRNA clones. Appl. Environ. Microbiol. 70:17871794.

Contreras, M., P.D. Loeza, J. Villegas, R. Farias, and G. Santoyo. 2016. A glimpse of the endophytic bacterial diversity in roots of blackberry plants (Rubus fruticosus). Genet. Mol. Res. 15(3):1-10.

Danhorn, T., and C. Fuqua. 2007. Biofilm formation by plant-associated bacteria. Annu. Rev. Microbiol. 61:401-422.

Doty, S.L., B. Oakley, G. Xin, J. Kang, G. Singleton, Z. Khan, et al. 2009. Diazotrophic endophytes of native black cottonwood and willow. Symbiosis 47:23-33.
Elvira-Recuenco, M., and J.W.L.V. Vuurde.2000. Natural incidence of endophytic bacteria in pea cultivars under field conditions. Can. J. Microbiol. 46:1036-1041.

Glick, B.R. 2014. Bacteria with ACC deaminase can promote plant growth and help to feed the world. Microbiol. Res. 169:30-39.

Granér, G., P. Persson, J. Meijer, and S. Alström. 2003. A study on microbial diversity in different cultivars of Brassica napus in relation to its wilt pathogen, Verticillium longisporum. FEMS Microbiol. Lett. 224:269-276.

Hallman, J., A. Quadt-Hallman, W.F. Mahaffee, and J.W. Kloepper. 1997. Bacterial endophytes in agricultural crops. Can. J. Microbiol. 43:895914.

Hernández-León, R., D. Rojas-Solís, M. ContrerasPérez, M.C. Orozco-Mosqueda, L.I. MacíasRodríguez, H. Reyes-de la Cruz, et al. . 2015. Characterization of the antifungal and plant growth-promoting effects of diffusible and volatile organic compounds produced by Pseudomonas fluorescens strains. Biolog. Contr 81:83-92.

Huang, C.J., J.F. Tsay, S.Y. Chang, H.P. Yang, W.S. Wu, and C.Y. Chen. 2012. Dimethyl disulfide is an induced systemic resistance elicitor produced by Bacillus cereus C1L. Pest Manag. Sci. 68:1306-1310.

Jakobi, M., Winkelmann, G., Kaiser, D., Kempter, C., Jung, G., Berg, G., et al. 1996. Maltophilin: A new antifungal compound produced by Stenotrophomonas maltophilia R3089. J. Antibiot 49:1101-1104.

Kumar, R.S., N. Ayyadurai, P. Pandiaraja, A.V. Reddy, Y. Venkateswarlu, O. Prakash, et al. 2005. Characterization of antifungal metabolite produced by a new strain Pseudomonas aeruginosa PUPa3 that exhibits broad-spectrum antifungal activity and biofertilizing traits. J. Appl. Microbiol. 98:145154.

Marquez-Santacruz, H.A., R. Hernandez-Leon, M.C. Orozco-Mosqueda, I. VelazquezSepulveda, and G. Santoyo. 2010. Diversity of bacterial endophytes in roots of Mexican husk tomato plants (Physalis ixocarpa) and their detection in the rhizosphere. Genet. Mol. Res. 9:2372-2380.

Martínez-Absalón, S., D. Rojas-Solís, R. Hernández-León, C. Prieto-Barajas, M.C. Orozco-Mosqueda, et al. 2014. Potential use and mode of action of the new strain Bacillus thuringiensis UM96 for the biological control of the grey mould phytopathogen Botrytis cinerea. Biocontrol Sci.Technol. 24:1349-1362. 
McInroy, J.A., y J.W. Kloepper. 1995. Survey of indigenous bacterial endophytes from cotton and sweet corn. Plant Soil 173:337-342.

Meldau, D.G., S. Meldau, L.H. Hoang, S. Underberg, H. Wünsche, and I.T. Baldwin. 2013. Dimethyl disulfide produced by the naturally associated bacterium Bacillus sp B55 promotes Nicotiana attenuata growth by enhancing sulfur nutrition. Plant Cell 25:27312747.

Noh Medina, J., C. Yam Chimal, L. Borges Gómez, J.J. Zúñiga Aguilar, y G. Godoy Hernández. 2014. Aislados bacterianos con potencial biofertilizante para plántulas de tomate. Terra Latinoamericana 32:273-281.

Pageni, B.B., N.Z. Lupwayi, Z. Akter, F.J. Larney, L.M. Kawchuk, and Y. Gan. 2014. Plant growthpromoting and phytopathogen-antagonistic properties of bacterial endophytes from potato (Solanum tuberosum L.) cropping systems. Can. J. Plant Sci. 94:835-844.

Patten, C.L., and B.R. Glick. 1996. Bacterial biosynthesis of indole-3-acetic acid. Can. J. Microbiol. 42:207-220.

Perez-Cordero, A.F., J.N. Rojas-Sierra, and J.R. Fuentes-Cuello. 2010. Diversidad de bacterias endófitas asociadas a raíces del pasto colosuana (Bothriochloa pertusa) en tres localidades del departamento de Sucre, Colombia. Acta Biol. Colomb. 15:219-228

Rojas-Solís, D., C.E. Hernández-Pacheco, y G. Santoyo. 2016. Evaluación de Bacillus y Pseudomonas para colonizar la rizosfera y su efecto en la promoción del crecimiento en tomate (Physalis ixocarpa Brot. ex Horm.). Rev. Chapingo. Ser. Hortic. 22:45-58.

Rosenblueth, M., and E. Martínez-Romero. 2006. Bacterial endophytes and their interactions with hosts. Molecular Plant-Microbe Interact. 19:827-837.

Santoyo, G., E. Valencia-Cantero, M.C. OrozcoMosqueda, J.J. Peña-Cabriales, y R. FaríasRodríguez. 2010. Papel de los sideróforos en la actividad antagónica de Pseudomonas fluorescens ZUM80 hacia hongos fitopatógenos. Terra Latinoamericana 28:53-60.

Santoyo, G., G. Moreno-Hagelsieb, M.C. OrozcoMosqueda, and B.R. Glick. 2016. Plant growth-promoting bacterial endophytes. Microbiological Research 183:92-99.

Schwyn, B., and J.B. Neilands 1987. Universal chemical assay for the detection and determination of siderophores. Anal. Biochem. 160:47-56.

Silver, S., and M. Walderhaug.1992. Gene regulation of plasmid-and chromosomedetermined inorganic iron transport in bacteria. Microbiol. Rev. 56:195-228.
Sørensen, J., and A. Sessitsch. 2007. Plant-associated bacteria-lifestyle and molecular interactions. p. 211-236. En Modern soil microbiology. CRC Press, Boca Raton, Florida, USA.

Sun, L., F. Qiu, X. Zhang, X. Dai, X. Dong, y W. Song. 2008. Endophytic bacterial diversity in rice (Oryza sativa L.) roots estimated by $16 \mathrm{~S}$ rDNA sequence analysis. Microbial Ecol. 55:415-424.

Sziderics, A.H., F. Rasche, F. Trognitz, A. Sessitsch, and E. Wilhelm. 2007. Bacterial endophytes contribute to abiotic stress adaptation in pepper plants (Capsicum annuum L.). Can. J. Microbiol. 53:1195-1202.

Szilagyi-zecchin, V., A.C. Ikeda, M. Hungria, D. Adamoski, V. Kava-cordeiro, C. Glienke, et al. 2014. Identification and characterization of endophytic bacteria from corn (Zea mays L.) roots with biotechnological potential in agriculture. AMB Express 4:1-9.

Tamura, K., D. Peterson, N. Peterson, G. Stecher, M. Nei, and S. Kumar. 2011. MEGA5: molecular evolutionary genetics analysis using maximum likelihood, evolutionary distance, and maximum parsimony methods. Mol. Biol. Evol. 28:2731-2739.

Turner, T.R., E.K. James, and P.S. Poole. 2013. The plant microbiome. Genome Biol. 14:209.

Wei, H.L., and L.Q. Zhang. 2006. Quorumsensing system influences root colonization and biological control ability in Pseudomonas fluorescens 2P24. Antonie van Leeuwenhoek 89:267-280.

Weisburg, W.G., S.M. Barns, D.A. Pelletier, and D.J. Lane. 1991. 16S ribosomal DNA amplification for phylogenetic study. J. Bacteriol. 173:697703.

Weller, D.M., J.M. Raaijmakers, B.B. Gardener, and L.S. Thomashow. 2002. Microbial populations responsible for specific soil suppressiveness to plant pathogens. Annu. Rev. Phytopathol. 40:309-48.

Zinniel, D.K., P. Lambrecht, N.B. Harris, Z. Feng, D. Kuczmarski, P. Higley, et al. 2002. Isolation and characterization of endophytic colonizing bacteria from agronomic crops and prairie plants. Appl. Environ. Microbiol. 68:21982208.

Zgadzaj, R., E.K. James, S. Kelly, Y. Kawaharada, N. Jonge, D.B. Jensen, et al. 2015. A legume genetic framework controls infection of nodules by symbiotic and endophytic bacteria. PLoS Genetics 11:e1005280. 